\title{
Síndrome de Burnout e os estressores relacionados à exaustão emocional em enfermeiros
}

\author{
Burnout Syndrome and stressors related to emotional exhaustion in nurses
}

\section{El Síndrome de agotamiento y los factores estresantes relacionados con el agotamiento emocional en las enfermeras}

Jeycianne Cristina dos Santos Bastos ${ }^{1 *}$, Juliane Carvalho Colares Gomes ${ }^{1}$, Vitória Vasconcelos de Castro $^{1}$, Matheus Moitinho Prata ${ }^{1}$, Joissy Carla Correia do Nascimento ${ }^{1}$, André Luiz Freitas Nogueira ${ }^{1}$, Lucas Pimenta Costa ${ }^{1}$, Crislene da Silva de Lima ${ }^{1}$, Samara Deuzuita de Almeida Sousa ${ }^{1}$, Graciana de Sousa Lopes².

\section{RESUMO}

Objetivo: Descrever os estressores que levam o profissional enfermeiro a desenvolver a Síndrome de Burnout. Métodos: Trata-se de uma pesquisa descritiva, explorativa, com abordagem qualitativa, do tipo revisão integrativa da literatura. Os artigos completos utilizados neste trabalho serão em português, inglês e disponibilizados gratuitamente por meio digital, publicados na última década. Resultados: Os artigos utilizados foram 15. E as plataformas utilizados para realização dos dados foram Scientific Electronic Library Online (SCIELO), (Literatura Latino-Americana e do Caribe em Ciências em Saúde (LILACS) e Biblioteca Virtual em Saúde (BVS). De tal forma observou-se que há uma unanimidade em torno do sintoma de desgaste físico, que afeta todos os profissionais de enfermagem causando o Burnout, assim como o desgaste mental e emocional que acaba por se desenvolver por meio do contato direto entre profissional e paciente. Considerações finais: Por tanto, observou-se que não só o estresse pode causar o desenvolvimento da Síndrome de Burnout, existindo inúmeros fatores de risco e sintomas que podem influenciar para o seu desenvolvimento levando a uma exaustão emocional.

Palavras-chave: Esgotamento psicológico, Pânico, Estresse psicológico, Enfermagem.

\section{ABSTRACT}

Objective: To describe the stressors that lead the professional nurse to develop the Burnout Syndrome. Methods: This is a descriptive, explorative research, with qualitative approach, of the integrative literature review type. The complete articles used in this work will be in Portuguese, English and made available free of charge through digital means, published in the last decade. Results: The articles used were 15. And the platforms used for the data were Scientific Electronic Library Online (SCIELO), (Latin American and Caribbean Literature on Health Sciences (LILACS) and Virtual Health Library (VHL). In such a way it was observed that there is a unanimity around the symptom of physical wear and tear, which affects all nursing professionals causing the Burnout, as well as the mental and emotional wear and tear that ends up developing through direct contact between professional and patient. Final considerations: Therefore, it was observed that not only stress can cause the development of the Burnout Syndrome, there are numerous risk factors and symptoms that can influence its development leading to emotional exhaustion.

Keywords: Psychological exhaustion, Panic, Psychological stress, Nursing.

\section{RESUMEN}

Objetivo: Describir los factores estresantes que llevan a la enfermera profesional a desarrollar el Síndrome de Quemadura. Métodos: Se trata de un enfoque descriptivo, exploratorio, cualitativo, del tipo de revisión de literatura integradora. Los artículos completos utilizados en este trabajo estarán en portugués, inglés y disponibles gratuitamente por medios digitales, publicados en la última década. Resultados: Los artículos utilizados fueron 15.

${ }^{1}$ Centro Universitário Fametro (CEUNI-FAMETRO), Manaus - AM. *E-mail: jeyciannebastos@gmail.com
${ }^{2}$ Universidade Federal do Amazonas (UFAM), Manaus - AM. 
Y las plataformas utilizadas para los datos fueron la Biblioteca Científica Electrónica en Línea (SCIELO), (Literatura Latinoamericana y del Caribe en Ciencias de la Salud (LILACS) y la Biblioteca Virtual en Salud (BVS). Así, se observó que hay unanimidad en torno al síntoma del desgaste físico, que afecta a todos los profesionales de la enfermería causando el agotamiento, así como el desgaste mental y emocional que finalmente se desarrolla a través del contacto directo entre el profesional y el paciente. Consideraciones finales: Por lo tanto, se observó que no sólo el estrés puede causar el desarrollo del Síndrome de Quemadura, sino que hay varios factores de riesgo y síntomas que pueden influir en su desarrollo llevando al agotamiento emocional.

Palabras clave: Agotamiento psicológico, Pánico, Estrés psicológico, Enfermería.

\section{INTRODUÇÃO}

O Ministério da Saúde (2019), caracteriza a síndrome de burnout, como uma doença psicossomática causada por diversos fatores que envolvem o trabalho ou o meio de convivência do indivíduo, principalmente em ambientes competitivos e que demandem muita responsabilidade. Esta exacerbação de atividades é comum em profissionais que convivem em ambientes sob pressão, incluindo os da saúde.

A enfermagem e a profissão mais afetadas por causa do estresse, pelo convívio que o enfermeiro tem com cliente no âmbito do processo da dor, sofrimento e morte. Ou por causa de situações que são repulsivas e triste por quem estar executando. A síndrome de burnout é causada pelo estresse crônico no trabalho, que causa dano físico, mental e a negatividade no trabalhador. Os profissionais de enfermagem relatam que por conta da enorme carga de trabalho, instabilidade, déficit de materiais e a baixa remuneração acabam adquirindo a síndrome (KUREBAYASHI LFS, et al., 2011; NOGUEIRA LS, et al., 2018).

Profissional que desenvolve o Burnout acaba perdendo estímulo e a vontade de trabalhar, impossibilitando uma boa assistência. Nesse âmbito há três tipos de dimensões que estão ligados a síndrome que são independentes, sendo: a exaustão emocional, despersonalização e a perda da realização pessoal no trabalho. A Exaustão emocional e a falta ou déficit de energia, que é causada pelo esgotamento emocional, podendo possuir duas formas de sintomas, seja física, mental ou ambas (RISSARDO MP e GASPARINO RC, 2013).

Despersonalização e a falta de emoção, perda de interesse no trabalho, o modo do tratamento do profissional com paciente, tratando-o de forma fria e indiferença. Possui ainda, sintomas característicos como, ansiedade, desmotivação, irritação, descomprometimento no trabalho, egoísmo e alienação. A perda de realização pessoal no trabalho e a auto avalição negativa de si, baixa autoestima, insatisfação, causando até mesmo abandono do trabalho. Muitos acabam se sentindo infelizes consigo mesmo e pelo seu desempenho profissional (RISSARDO MP e GASPARINO RC, 2013).

Relacionado ao Burnout é possível citar a depressão, que é o sofrimento psíquico nos profissionais de enfermagem, devido aos pensamentos negativos, insônia, fadiga, desanimo, angústia, medo, sentimento de culpa, alteração de humor e a falta de apetite. O Burnout pode ser confundido e diagnosticado como depressão podendo levar a um tratamento que não e adequado, agravando ainda mais a doença (VASCONCELOS EM, et al., 2017).

Pode-se observar que elas são diferentes pela fisiologia, a depressão é causada pela fisiopatologia devido há um trauma intrínseco, e o Burnout não, ele tem sua fisiopatologia causado pelo trabalho. Sendo importante analisar os sintomas entre elas, afim de encontrar um resultado que ajude na elaboração de programas para prevenções e detecções da doença (VASCONCELOS EM, et al., 2017).

Possuir conhecimento sobre o Burnout é importante para o desenvolvimento de estratégias e medidas de prevenção, já que os profissionais mais afetados são os da área da saúde. Assim, conhecer o Burnout é importante pois ajuda a saber sobre os fatores relacionados a ele e a doença, mais também diferenciá-las tanto fisiologicamente como psicologicamente ajudando na busca de ações para detectar e prevenir ela NOGUEIRA LS, et al., 2018). Evidenciando-se que a Síndrome de Burnout afeta mais os profissionais de saúde de forma constante, devido estarem mais expostos a fatores que acabam desenvolvendo os sintomas (RISSARDO MP e GASPARINO RC, 2013). 
Diante do cenário de estudos, faz-se necessário apresentar está abordagem para uma melhor compreensão da temática, e propiciar o aumento das produções científicas. Desta forma, o objetivo deste estudo é descrever os estressores que levam o profissional de enfermagem desenvolver o Burnout, caracterizando-se como um problema de saúde pública. Descrevendo medidas e estratégias que ajudem a melhorar o ambiente de trabalho, tornando mais leve e menos estressante $o$ ambiente de trabalho pela equipe de enfermagem.

\section{MÉTODOS}

Trata-se de uma pesquisa descritiva, explorativa, com abordagem qualitativa, do tipo revisão integrativa da literatura. As bibliotecas virtuais a serem utilizadas foram SCIELO, BVS e LILACS. Os artigos serão elencados de acordo com os seguintes critérios de Elegibilidade: Artigos em Português e Inglês, disponíveis gratuitamente completos, publicados nos últimos 10 anos (2010-2019), para busca de conhecimento na temática abordada e para obtenção dados.

Os critérios de Inelegibilidade foram: Artigos em formato de Resumo, monografias, dissertações e teses de doutorados. Utilizou-se os Descritores em Ciências da Saúde (DECS): Esgotamento Psicológico, Pânico, Estresse Psicológico; Enfermagem. Os artigos foram selecionados de acordo com os critérios estabelecidos, e posteriormente foi realizada a análise de resumos e finalmente os artigos foram lidos na integra, sendo elaborado um instrumento para a coleta de informações direto das bases de dados (Figura 1).

Figura 1 - Fluxograma dos artigos encontrados nas bases de dados.
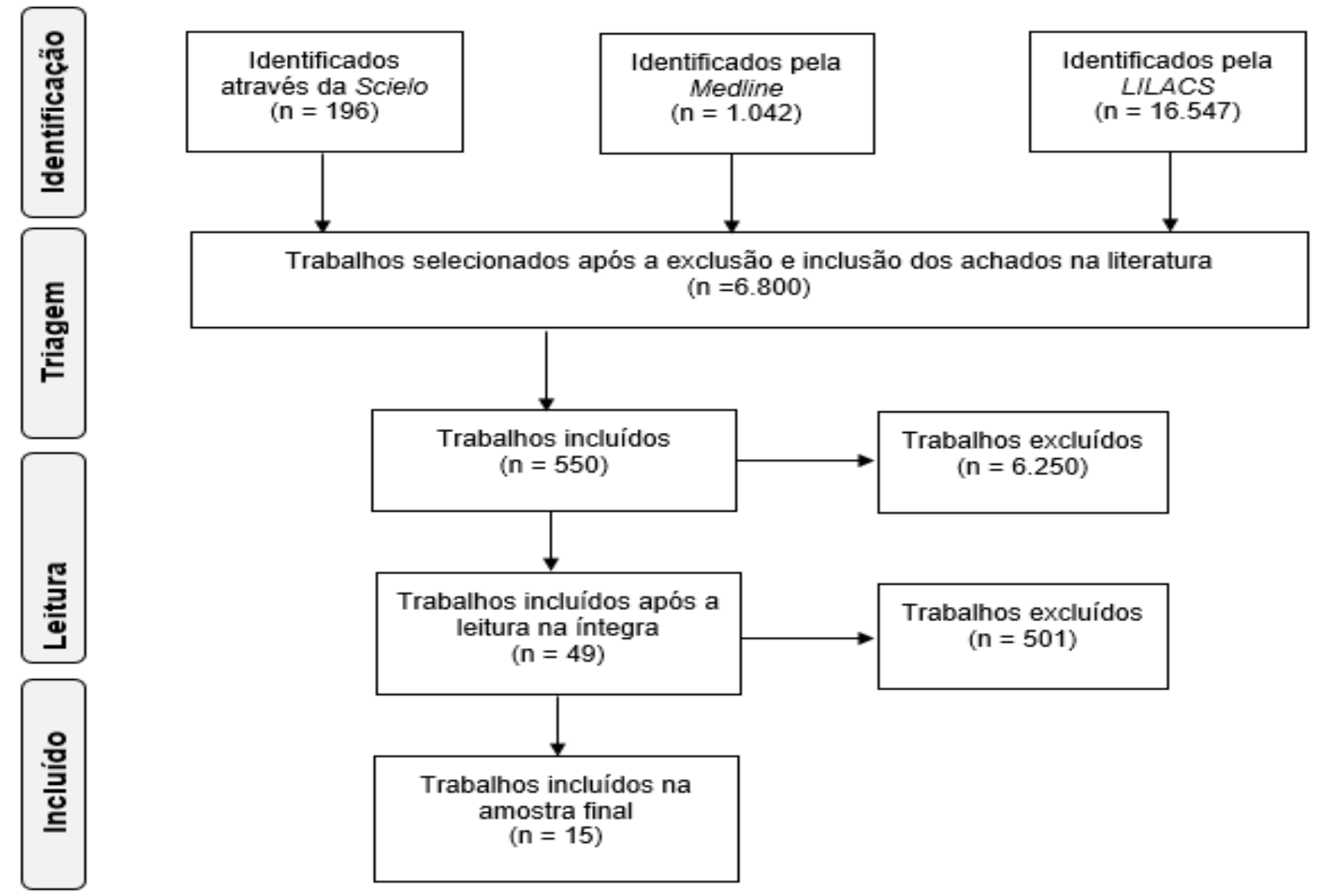

Fonte: Bastos JCS, et al., 2020.

\section{RESULTADOS E DISCUSSÃO}

Os artigos utilizados foram 15, sendo eles 11 em português e 4 em inglês. Conforme descrito anteriormente, foram selecionados alguns dos artigos científicos nacionais e internacionais, estes artigos servirão de base para discutir e argumentar, os resultados de acordo com o tema e os objetivos desse trabalho (Quadro 1). 
Quadro 1 - Artigos selecionados para composição dos resultados e discussão.

\begin{tabular}{|c|c|c|c|c|c|c|}
\hline & TíTULO & AUTOR & ANO & IDIOMA & PLATAFORMA & RESULTADOS \\
\hline 1 & $\begin{array}{l}\text { Burnout entre os Profissionais } \\
\text { de Enfermagem em Hospitais } \\
\text { no Brasil. }\end{array}$ & DUTRA HS, et al., & 2018 & Português & SCIELO & $\begin{array}{l}\text { Fadiga, alteração no sono, sobrecarga de } \\
\text { trabalho, jornadas de trabalho longas e } \\
\text { exaustivas, falta de reconhecimento no trabalho, } \\
\text { a convivência com a dor, sofrimento e morte nos } \\
\text { hospitais. São fatores relacionado ao Burnout. }\end{array}$ \\
\hline 2 & $\begin{array}{l}\text { Preditores da Síndrome de } \\
\text { Burnout em Enfermeiros de } \\
\text { Unidade de Terapia Intensiva. }\end{array}$ & $\begin{array}{l}\text { VASCONCELOS EM, } \\
\text { et al., }\end{array}$ & 2017 & Português & SCIELO & $\begin{array}{l}\text { Os sintomas sentidos relacionado ao Burnout } \\
\text { são: irritabilidade, esgotamento físico e mental. } \\
\text { Outros fatores ligados ao Burnout são turno de } \\
\text { trabalho, baixa remuneração, plantões noturnos, } \\
\text { jornada de trabalho exaustiva são uns dos } \\
\text { fatores ligados ao Burnout na terapia intensiva. }\end{array}$ \\
\hline 3 & $\begin{array}{l}\text { Síndrome de Burnout e o } \\
\text { Trabalho em Turnos na Equipe } \\
\text { de Enfermagem. }\end{array}$ & VIDOTTI V, et al., & 2018 & Inglês & SCIELO & $\begin{array}{l}\text { Os salários baixos, convívio com sofrimento e a } \\
\text { morte, desmotivação e outros fatores são } \\
\text { relacionados a Síndrome de Burnout. }\end{array}$ \\
\hline 4 & $\begin{array}{l}\text { Trabalho em turnos de } \\
\text { Profissionais de Enfermagem e } \\
\text { a Pressão Arterial, Burnout e } \\
\text { Transtornos Mentais Comuns. }\end{array}$ & $\begin{array}{l}\text { NASCIMENTO JOV, } \\
\text { et al., }\end{array}$ & 2018 & Inglês & SCIELO & $\begin{array}{l}\text { Há vários fatores que são relacionados ao } \\
\text { Burnout seja por sintomas ou estressores dentre } \\
\text { eles são: Insônia, dores de cabeça, irritabilidade, } \\
\text { fadiga crônica, baixa remuneração, plantões } \\
\text { noturnos, dupla jornadas de trabalho. }\end{array}$ \\
\hline 5 & $\begin{array}{l}\text { Avaliação do Burnout em } \\
\text { Enfermeiros de um Serviço de } \\
\text { Urgência Geral. }\end{array}$ & NOBRE DFR, et al., & 2019 & Inglês & SCIELO & $\begin{array}{l}\text { Na urgência o desgaste físico e mental, turno no } \\
\text { trabalho, o modo de lidar e convívio com } \\
\text { sofrimento e a morte do cliente são os fatores } \\
\text { que podem causa a Síndrome de Burnout. }\end{array}$ \\
\hline 6 & $\begin{array}{l}\text { Enfermagem em Nefrologia e } \\
\text { Síndrome de Burnout. }\end{array}$ & FERREIRA TC, et al., & 2012 & Português & LILACS & $\begin{array}{l}\text { Na nefrologia observou que desgaste físico e } \\
\text { mental e o sintoma que causa o Burnout. Assim } \\
\text { como turnos no trabalho, jornada dupla de } \\
\text { trabalho. }\end{array}$ \\
\hline
\end{tabular}




\begin{tabular}{|c|c|c|c|c|c|c|}
\hline & TíTULO & AUTOR & ANO & IDIOMA & PLATAFORMA & RESULTADOS \\
\hline 7 & $\begin{array}{l}\text { Incidência da Síndrome de } \\
\text { Burnout nos Profissionais de } \\
\text { Enfermagem: ‘Uma Revisão } \\
\text { Integrativa. }\end{array}$ & OLIVEIRA RF, et al., & 2017 & Português & LILACS & $\begin{array}{l}\text { Há fatores vários fatores ligados ao Burnout } \\
\text { como: esgotamento emocional e físico, } \\
\text { desmotivação. As duplas jornadas, baixa } \\
\text { remuneração, sobrecarga de trabalho. }\end{array}$ \\
\hline 8 & $\begin{array}{l}\text { Síndrome de Burnout entre } \\
\text { Enfermeiros de um Hospital } \\
\text { Geral da Cidade do Recife. }\end{array}$ & GALINDO RH, et al., & 2012 & Português & LILACS & $\begin{array}{l}\text { O Burnout pode causar, cefaleia, irritabilidade, } \\
\text { fadiga crônica, insônia, desgaste físico e mental. } \\
\text { Há fatores e estressores que desenvolvem o } \\
\text { Burnout como: dupla jornada de trabalho, baixo } \\
\text { realização profissional, trabalho por tuno/ou } \\
\text { noturno, sobrecarga de trabalho e outros. }\end{array}$ \\
\hline 9 & $\begin{array}{l}\text { Burnout e Estresse em } \\
\text { Enfermeiros de um Hospital } \\
\text { Universitário de Alta } \\
\text { Complexidade. }\end{array}$ & LORENZ VR, et al., & 2010 & Inglês & LILACS & $\begin{array}{l}\text { A síndrome de Burnout pode apresentar: } \\
\text { desgaste emocional e físico, aumento da } \\
\text { irritabilidade. Como também e relacionado há } \\
\text { falta de reconhecimento do trabalho realizado, } \\
\text { baixa realização profissional, prolongadas } \\
\text { jornadas de trabalho. }\end{array}$ \\
\hline 10 & $\begin{array}{l}\text { Síndrome de Burnout e } \\
\text { Absenteísmo em Enfermeiros } \\
\text { no Contexto Hospitalar: Revisão } \\
\text { Integrativa da Literatura } \\
\text { Brasileira. }\end{array}$ & RESENDE R, et al., & 2012 & Português & LILACS & $\begin{array}{l}\text { Os fatores e os estressores podem estar } \\
\text { relacionados há: Baixa remuneração, dupla } \\
\text { jornada de trabalho, esgotamento profissional, } \\
\text { desgaste físico e mental. }\end{array}$ \\
\hline 11 & $\begin{array}{l}\text { Síndrome de Burnout na Equipe } \\
\text { de Enfermagem de um Hospital } \\
\text { Universitário. }\end{array}$ & $\begin{array}{l}\text { RISSARDO MP e } \\
\text { GASPARINO RC, }\end{array}$ & 2013 & Português & BVS & $\begin{array}{l}\text { Baixo salário, sobrecarga de trabalho, trabalho } \\
\text { no período noturno, falta de reconhecimento e } \\
\text { são fatores relacionado ao Burnout. Como } \\
\text { também os sintomas que são: cefaleia, fadiga } \\
\text { crônica, distúrbios do sono, desgaste físico e } \\
\text { emocional. }\end{array}$ \\
\hline
\end{tabular}




\begin{tabular}{|c|c|c|c|c|c|c|}
\hline & TíTULO & AUTOR & ANO & IDIOMA & PLATAFORMA & RESULTADOS \\
\hline 12 & $\begin{array}{l}\text { Predisposição para Síndrome } \\
\text { de Burnout na Equipe de } \\
\text { Enfermagem do Serviço de } \\
\text { Atendimento Móvel de Urgência. }\end{array}$ & SILVA FG, et al., & 2019 & Português & BVS & $\begin{array}{l}\text { No Burnout pode apresentar fadiga, irritabilidade, } \\
\text { desmotivação, desgaste físico e emocional, } \\
\text { devido a jornada dupla de trabalho, sobrecarga } \\
\text { de trabalho. }\end{array}$ \\
\hline 13 & $\begin{array}{l}\text { Síndrome de Burnout: Impacto } \\
\text { da Satisfação no Trabalho e da } \\
\text { Percepção de Suporte } \\
\text { Organizacional. }\end{array}$ & NEVES VF, et al., & 2014 & Português & BVS & $\begin{array}{l}\text { Baixa realização pessoal no trabalho, longas } \\
\text { jornada de trabalho, falta de reconhecimento. } \\
\text { contato diário com paciente no estado de } \\
\text { sofrimento, dor e morte. A sobrecarga de } \\
\text { trabalho, desgaste físico e emocional. }\end{array}$ \\
\hline 14 & $\begin{array}{l}\text { Síndrome de Burnout em } \\
\text { Trabalhadores de Enfermagem } \\
\text { da Atenção Básica à Saúde. }\end{array}$ & MERCES MC, et al., & 2016 & Português & BVS & $\begin{array}{l}\text { Na atenção básica de saúde podemos observar } \\
\text { que: Salários baixos, desmotivação, jornada de } \\
\text { trabalho, convivência com a adversidade, a } \\
\text { doenças e a morte dos pacientes pode acabar } \\
\text { causando o Burnout devido ao alto nível de } \\
\text { estresse. }\end{array}$ \\
\hline 15 & $\begin{array}{l}\text { Discussão Sobre as Causas da } \\
\text { Síndrome de Burnout suas } \\
\text { Implicações à Saúde do } \\
\text { Profissional de Enfermagem. }\end{array}$ & SILVA JLL, et al., & 2012 & Português & SCIELO & $\begin{array}{l}\text { A SB pode apresentar vários sintomas entre eles } \\
\text { tem: fadiga, irritabilidade, cefaleia, distúrbio no } \\
\text { sono, dentre outros. E há outros fatores } \\
\text { relacionados como: Longas jornadas de } \\
\text { trabalho, baixa remuneração, sobrecarga de } \\
\text { trabalho, contato direto com sofrimento, dor, } \\
\text { morte. }\end{array}$ \\
\hline
\end{tabular}

Fonte: Bastos JCS, et al., 2020. 
Após a análise dos achados, escolheu-se duas categorias, para melhor compreensão do assunto e alcance do objetivo deste estudo.

\section{Categoria I: principais sintomas da síndrome de Burnout em enfermeiros.}

A enfermagem e a profissão mais afetadas por causa do estresse, pelo convívio que o enfermeiro tem com cliente no âmbito do processo da dor, sofrimento e morte. Ou por causa de situações que são repulsivas e triste por quem estar executando (KUREBAYASHI LFS, et al., 2011). Há uma resistência ao estresse psicológico e seus sintomas, que são mascarados por muitos. Mostrando que está tudo bem com o controle de tudo, mas com o tempo vai se tornando difícil de esconder seus sentimentos e sintomas acabando que tudo vem à tona de uma vez só (FARIAS SMC, et al., 2011).

Hospital acabar por ser o local que os profissionais sofrem muito mais, devido ter pouco profissional, há dificuldade trabalhar em equipe, o alto nível de trabalho a ser feito e devido ao salário que acaba fazendo os funcionários trabalhem mais resultando em uma enorme carga de trabalho e exaustiva prejudicando 0 psicológico profissional (COSTA DT e MARTINS MCF, 2011).

Os sintomas mais comuns sentidos que os profissionais relatam são as dores de cabeça por causa de tensão ou dor muscular, ou pela fadiga sentida. Tal sintomas são ligados a Síndrome de Burnout que e o resultado pelo esgotamento físico e mental, devido ao estresse crônico que desencadear vários outros tipos de sintomatologias como: sensação de desanimo, insônia, falta de apetite, taquicardia, tremores musculares e vários outros (FARIAS SMC, et al., 2011).

De acordo com Nobre DFR, et al. (2019), há uma unanimidade em torno do sintoma de desgaste físico, que afeta todos os profissionais de enfermagem causando o Burnout. Ele está relacionado há uma sobrecarga de trabalho, pela baixa remuneração, devido a jornada dupla de trabalho, trabalho por turno/noturno, falta de reconhecimento, baixo salário, baixa realização no trabalho, sobrecarga, o contato direto com paciente no estado de sofrimento, dor e morte (FERREIRA TC, et al., 2012; SILVA FG, et al., 2019).

A desvalorização e a falta de reconhecimento da enfermagem é uma luta constantemente discutida. Embora a satisfação profissional mostrada nos resultados seja um ponto que apoie a ideia de suportar a síndrome, os profissionais de enfermagem sofrem de forma rotineira a essa desvalorização, com salários reduzidos e sobrecarga de trabalho.

O desgaste físico pode estar relacionado de forma direta com o trabalho intenso devido a uma rotina que demanda de uma atenção constante aos pacientes, bem como saber lidar com situações críticas como na urgência. O profissional acaba por se sentir esgotado e sem vontade de trabalhar. Há uma necessidade de ser comunicado que está ocorrendo, pois, o seu comportamento muda completamente ele fica completamente irritados a sons e não consegue realizar mais seu trabalho normalmente (COELHO JAB, et al., 2010; MARTINS CCF, et al., 2012).

Existe uma unanimidade que entorno do sintoma da fadiga que causa o Burnout nos enfermeiros. Que estão ligados a sobrecarga de trabalho, jorna dupla de trabalho, baixa remuneração, falta de reconhecimento no trabalho, trabalho por turno/noturno, baixo salário, sobrecarga horária e a convivência com a dor, sofrimento e morte do paciente (DUTRA HS, et al., 2012; GALINDO RH, et al., 2018; NASCIMENTO JOV, et al., 2018).

Neste sentido a fadiga em si, é um processo de exaustão física e psíquica que faz alteração no estado de alerta e vigilância do profissional, que afeta as habilidades do enfermeiro na hora de realizar atividades ocupacionais. Logo se nota que se apresenta apenas como um processo que ocorre fisiologicamente, mais pode acabar evoluindo pra um estado de fadiga crônica (SILVA TPD, et al., 2018).

Devido há um enorme atendimento, os profissionais acabam por ter que ser ágeis e rápidos nas tomadas das decisões, ainda mais quando o paciente se encontra em estado crítico e não pode esperar muito tempo e nem que tenhas falhas de conduta na assistência prestada o que só prejudicar a saúde e acaba por causa o esgotamento no enfermeiro. Esse esgotamento que é conhecido por ser um transtorno, pois vai interferir na vida social do profissional, ocasionando desinteresse no trabalho e irritabilidade, acabando que o profissional adoece e seu rendimento baixo (VITORINO MF, et al., 2018; OLIVEIRA APS, et al., 2019). 
A irritabilidade e correlacionada há exposição que os profissionais, tem no trabalho devido aos ruídos e ao ambiente que possuem radiações ionizantes nele, assim como as causas de cefaleia. Foi verificado que situações de estresse nos profissionais, estão associadas as lesões musculoesqueléticas principalmente nas áreas do pescoço, ombros, costas e cintura que acabam adquirindo. $\mathrm{E}$ o fator de odores desagradáveis acabarem causando irritação nos profissionais, existindo ainda uma unanimidade que altera o padrão do sono, afetando o profissional, contribuindo no desenvolvimento do Burnout (NASCIMENTO JOV, et al., 2018; CARVALHO DP, et al., 2019).

O trabalho é uma fonte de satisfação pessoal e autorrealização, contudo, a exposição aos riscos pode levar ao surgimento de patologias, principalmente as mentais, como o Burnout. Estudos apontam um crescimento significativo da relação profissão-síndrome que paulatinamente cresce, afetando na qualidade da assistência prestada, sendo sentida pelos clientes e assistidos (NOBRE DFR, et al., 2019).

Em muitos momentos estressantes o profissional a perda do controle da situação, causando um sentimento de impotência em meio a situação atual. E isso traz um sentimento de revolta porque não há como reverter a situação ou de fazer o necessário pelo paciente. E o trabalho se torna um lugar de sofrimento, onde o profissional perde o prazer de realizar as atividades, tendo diminuição da carga psíquica. Todavia se essa carga de pressão aumenta, vai causar aumento também no trabalho e sua liberdade acaba diminuindo causando desmotivação em realizar qualquer atendimento e procedimento no paciente (DUARTE MLC, et al., 2018).

O estresse é visto como uma reação fisiológica a alguma ameaça ou situação de perigo em que somos expostos, sendo desencadeada por estressores e colocando o organismo em estado de alerta, alterando o emocional e o físico do indivíduo (BVS, 2015). Urbanetto JS, et al. (2019), descrevem que as características do estresse podem ser observadas diariamente e a variedade de estressores presentes podem variar substancialmente, desencadeando agravos à saúde

Neste sentido, os trabalhos longos e exaustivos, acabam que causando distúrbio no sono. Assim como o sono na parte diurna do trabalho, que tem a diminuição do estado de alerta. Todavia com a má qualidade do sono traz alterações que podem causar ferimentos, como na vida deles os profissionais já que eles têm pouco tempo de descanso no trabalho e suas cargas horário de trabalho são muito altas (RATOCHINSKI CMW, et al., 2016; PADILHA KG, et al., 2017).

\section{Categoria II: fatores de risco que causam o Burnout}

Neste sentido devido ter muito trabalho acaba que o profissional torna o muito exaustivo. Mas devido a isso há um sentimento de não conseguir realizar todos as demandas, que foram dadas pra ser realizadas nos pacientes. Em torno disso o profissional acaba por não ter espaço para executar nem planejar ações, pois possui pouco espaço para se ter uma discussão no trabalho. E o profissional que já possui uma qualificação melhor em uma área acabar por não ter suporte para se debater sobre o que está acontecendo é sugerir modificações e adaptações. Assim muitas vezes o profissional jovem que começa a trabalhar na área acaba por se sobrecarregar, assumindo o controle no atendimento em pacientes mais graves e até mesmo assumindo uma gerencia (FRANCO GP, et al., 2011; DUARTE MLC, et al., 2018).

De acordo com Neves FV, et al. (2014), concordam que o convívio e o contato diário e direto, com sofrimento, dor e morte dos pacientes acabam se tornam um risco aos profissionais causando 0 desenvolvimento da Síndrome de Burnout. E relacionado há uma enorme sobrecarga de trabalho, salário baixo, carga horária de trabalho, dupla jornada de trabalho e plantões noturnos. O profissional fica desmotivado, com desgaste físico e mental, vai se sentir insatisfeito, com fadiga, cefaleia e dores musculares (SILVA LLC, et al., 2012; MERCES MC, et al., 2016).

O profissional acaba por exigir de si mesmo para que tenha um controle sobre seu emocional, ainda mais na área da saúde. O enfermeiro passa muito tempo com paciente convivendo com ele, que acaba tendo um envolvimento, já que possui rotinas e são muitos exigentes e pela deficiência que o hospital muitas vezes tem e deixa a desejar. Isso causa um nível de estresse muito alta no profissional que atuam na área da saúde (FREITAS AR, et al., 2014, RATOCHINSKI CMW, et al., 2016). 
De acordo com Lorenz VR, et al. (2010), corroboram que, a baixa realização pessoal no trabalho e um fator de risco importante, que agrega para o desenvolvimento da Síndrome de Burnout. Que está correlacionado há trabalhos por turnos/noturno, falta de reconhecimento no trabalho, longas jornadas de trabalho. E acabam desenvolvendo sintomas como cefaleia, fadiga, insônia, irritabilidade, desgaste emocional e físico prejudicando o enfermeiro e no seu atendimento ao paciente (NEVES FV, et al., 2014).

Rivas EB e Macias A (2018), discutem que o estresse laboral na equipe de enfermagem é comum, devido a todas as suas variáveis e determinantes. Dupla jornada de trabalho, exposição a riscos, cobranças da equipe e diminuição do seu tempo de lazer. O estresse expressado de forma contínua e persistente, aliado a todos os fatores supracitados, podem gerar o desenvolvimento da SB. Vale ressaltar que o desenvolvimento da doença é multifatorial, que se origina desde uma cobrança excessiva até a percepção de estressores no ambiente de trabalho.

Neste sentido a baixa realização profissional se dá, nos profissionais que tem contato próximo e direto com os pacientes. O que leva a adquirir sentimentos e atitudes a sua avaliação na hora de atender os pacientes, e quanto a sua competência de realizar procedimentos. Todavia os mais jovens são mais propensos a ter esses sentimentos já que querem prestar serviço e são novos na área da saúde (FRANCO GP, et al., 2011; MORENO VPCP, et al., 2018).

Neste contexto, a maioria dos enfermeiros possuem outro emprego onde, ultrapassa mais de 80 horas por semana. Que causara impacto na vida do profissional e na assistência prestada ao paciente e contribuirá no desenvolvimento da Síndrome do Burnout. Se a unidade não possui uma estrutura de boa qualidade, bem como, não dispor de pessoal suficiente, pode gerar desgaste a saúde do profissional, que terá uma grande dificuldade em atender e presta serviço ao paciente, correlacionando-se a dupla jornada de trabalho, e o fato de realizar horas extras ao invés do lazer, acaba por proporcionar uma carência no período de descanso (SILVA TPD, et al., 2018; CARVALHO DP, et al., 2019).

O cansaço mental aliado a sobrecarga de trabalho afeta na qualidade da assistência de enfermagem prestada. Em uma revisão de natureza qualitativa, não apenas os fatores supracitados influenciam, também como a insegurança na execução dos serviços ao paciente, bem como a falta de educação continuada e atualizações pertinentes à área de atuação e também a sensação de impotência, aliada à frustração, que culminam em um nível elevado de estresse, corroborando com a resistência ao desgaste psicológico (VALERETTO FA e ALVES DF, 2013)

$\mathrm{Na}$ área de enfermagem os profissionais sofrem muita desvalorização, sendo pouco reconhecidos e até mesmo em que as expectativas não estejam do modo desejado e sonhado quando iniciou, os anos passam e o que fica é o sentimento de frustação. Há poucas pessoas pra suprir a demanda de pacientes e acaba tendo excesso de atividade o que gera frustração ao enfermeiro (MORENO VPCP, et al., 2018).

O trabalho por turno, por sua vez acaba por se destacar em ser um local estressante que influencia bastante em repercussões negativas, que afetam a saúde, podendo melhorar ou não, e isso depende das condições de vida e do trabalho. Outro fator a ser discutido, refere-se ao fato de que o enfermeiro trabalha em outro local, que exige uma dedicação maior e isso se dá pelo fato de que o profissional necessita de uma renda familiar maior, o que é bastante comum em quem trabalha na área da saúde (MENDES SS e MARTINO MMF, 2012; TRINDADE LL, et al., 2010).

Um fator relevante é o apoio social, pois o apoio de familiares, gestores e sociedade com a profissão é importante para que haja melhor compreensão do papel profissional e o respeito do seu espaço, além da luta pela valorização. Tanto que é considerado uma ferramenta importante para o enfrentamento do estresse, pois auxilia no entendimento de problemas e na adoção de um estilo de vida mais saudável. Este fator pode ser visto desde a academia, pois um estudo transversal, de abordagem quantitativa, realizado em uma universidade pública do interior de São Paulo, identificou que o apoio social gera impactos na vida do acadêmico que podem partir para a formação profissional, formando profissionais questionadores da sua profissão, como bem visto na insatisfação profissional abordada nos resultados deste estudo (ALMEIDA LY, et al., 2018). 
Deste modo, a baixa remuneração, acaba por influenciar nas decisões dos enfermeiros, fazendo com que ele procure outro trabalho devido à crise econômica, exigindo uma carga horária de trabalho maior, influenciando de forma prejudicial nos serviços ofertados, levando a um maior grau de acidentes, podendo estes ser reversíveis ou não, tanto ao paciente quanto em si (MENDES SS e MARTINO MMF 2012; TRINDADE LL, et al., 2010).

\section{CONSIDERAÇÕES FINAIS}

No presente trabalho observou-se que, não só o estresse pode causar o desenvolvimento da Síndrome de Burnout, mas que há inúmeros fatores de risco e sintomas que podem influenciar para o seu desenvolvimento, podendo levar a uma exaustão emocional. Os trabalhos dentro das unidades hospitalares já são fortes intermediários para que um profissional possa ser candidato a um possível problema de saúde mental, pois o público mais acometido são os profissionais da enfermagem, e para prevenção de qualquer tipo de sofrimento ao profissional e necessário que haja programas e condutas que possam levar o enfermeiro a uma boa promoção de saúde mental, afim de evitar que ele desenvolva o Burnout.

\section{REFERÊNCIAS}

1. CARVALHO DP, et al. Cargas de trabalho e os desgastes à saúde dos trabalhadores da enfermagem. Rev. Bras. Enferm, Brasília, 2019; 72(6): 1984-0446.

2. COELHO JAB, et al. Desgaste da equipe de enfermagem no centro de tratamento de queimados. Acta paul. enferm, São Paulo, 2010; 23(1):60-4.

3. COSTA DT e MARTINS MCF. Estresse em profissionais de enfermagem: impacto do conflito no grupo e do poder do médico. Rev. esc. enferm. USP, São Paulo, 2011; 45(5):1191-1198.

4. DUARTE MLC, et al. O trabalho em emergência hospitalar: sofrimento e estratégias defensivas dos enfermeiros. Rev. Gaúcha Enferm., Porto Alegre, 2018; 39:e2017-0255.

5. DUTRA HS, et al. Burnout entre profissionais de enfermagem em hospitais no Brasil. Rev Cuid, Bucaramanga, 2019; 10(1): e585.

6. FARIAS SMC, et al. Caracterização dos sintomas físicos de estresse na equipe de pronto atendimento. Rev. esc. enferm. USP, São Paulo, 2011; 45(3):722-9.

7. FERREIRA TC, et al. Enfermagem em nefrologia e Síndrome de Burnout. Cogitare enferm. Curitiba, $2012 ; 17(1): 449$.

8. FREITAS AR, et al. Impact of a physical activity program on the anxiety, depression, occupational stress and burnout syndrome of nursing professionals. Rev. Latino-Am. Enfermagem, Ribeirão Preto, 2014; 22(2): 332-6.

9. GALINDO RH, et al. Síndrome de Burnout entre enfermeiros de um hospital geral da cidade do Recife. Rev. esc. enferm. USP, São Paulo, 2012; 46(2): 420-42.

10. GASPARINO' RC. Síndrome de Burnout na equipe de enfermagem de um hospital universitário. Cogitare enferm., Curitiba, 2014; 19(2): 232-238.

11. KUREBAYASHI LFS, et al. Aplicabilidade da auriculoterapia com agulhas ou sementes para diminuição de estresse em profissionais de enfermagem. Rev. esc. enferm. USP, São Paulo, 2012, 46(1): 89-95.

12. LORENZ VR, et al. Burnout and Stress Among Nurses in a University Tertiary Hospital. Rev. Latino-Am. Enfermagem, Ribeirão Preto, 2010; 18(6): 1084-1091.

13. MENDES SS, MARTINO MMF. Trabalho em turnos: estado geral de saúde relacionado ao sono em trabalhadores de enfermagem. Rev. esc. enferm. USP, São Paulo, 2012; 46(6): 1471-1476.

14. MERCES MC, et al. Síndrome de Burnout em trabalhadores de enfermagem da atenção básica à saúde. Revista Baiana de Enfermagem, Salvador, 2016;30(3): 1-9.

15. MORENO VPCP, et al. Síndrome de burnout e fatores de estresse em enfermeiras nefrologistas. Revista de Enfermagem UFPE on line, [SI], 2018; 12(4): 865-871.

16. NASCIMENTO JOV, et al. Shift work of nursing professionals and blood pressure, burnout and common mental disorders. Rev. esc. enferm. USP, São Paulo, 2019; (53): e03443.

17. NEVES VF, et al. Síndrome de Burnout: Impacto da Satisfação no Trabalho e da Percepção de Suporte Organizacional. Psico, Porto Alegre, PUCRS, 2014; 45(1): 45-54.

18. NOBRE DFR, et al. Burnout assessment in nurses from a general emergency service. Rev. Bras. Enferm., Brasília, 2019; $72(6): 1457-1463$.

19. NOGUEIRA LS, et al. Burnout and nursing work environment in public health institutions. Rev. Bras. Enferm., Brasília, 2018; $71(2): 336-342$.

20. PADILHA KG, et al. Carga de trabalho de enfermagem, estresse/burnout, satisfação e incidentes em unidade de terapia intensiva de trauma. Texto contexto - enferm., Florianópolis, 2017; 26(3):e1720016.

21. RATOCHINSKI CMW, et al. O Estresse em Profissionais de Enfermagem: Uma Revisão Sistemática/ Stress in Nursing Professionals: A Systematic Review. Revista brasileira de ciência da saúde, 2016;20(4):341-346.

22. RISSARDO MP, GASPARINO RC. Exaustão emocional em enfermeiros de um hospital público. Esc. Anna Nery, Rio de Janeiro, 2013; 17(1): 128-132.

23. SILVA TPD, et al. Desconforto musculoesquelético, capacidade de trabalho e fadiga em profissionais da enfermagem que atuam em ambiente hospitalar. Rev. esc. enferm. USP, São Paulo, 2018; 52:e03332.

24. TRINDADE LL, et al. Estresse e síndrome de burnout entre trabalhadores da equipe de Saúde da Família. Acta paul. enferm., São Paulo, 2010; 23(5): 684-689.

25. VASCÓNCELOS EM, et al. Burnout and depressive symptoms in intensive care nurses: relationship analysis. Rev. Bras. Enferm., Brasília, 2018; 71(1): 135-141.

26. VASCONCELOS EM, et al. Preditores da síndrome de burnout em enfermeiros de unidade de terapia intensiva. Rev. Gaúcha Enferm., Porto Alegre, 2017; 38(4):e65354.

27. VIDOTTI V, et al. Burnout Syndrome and shift work among the nursing staff. Rev. Latino-Am. Enfermagem, Ribeirão Preto, 2018; 26:e3022..

28. VITORINO MF, et al. Síndrome de Burnout: conhecimento da equipe de enfermagem neonatal. Revista de Enfermagem UFPE on line, [SI], 2018; 12(9): 2308-2314. 